\title{
Social Cognitive Theory and Health Care: Analysis and Evaluation
}

\author{
Natalia I. Manjarres-Posada ${ }^{1}$, Dora J. Onofre-Rodríguez ${ }^{1} \&$ Raquel A. Benavides-Torres $^{1}$ \\ ${ }^{1}$ Faculty of Nursing, Autonomous University of Nuevo León, Monterrey, México \\ Correspondence: Raquel A. Benavides-Torres, Faculty of Nursing, Autonomous University of Nuevo León, Gonzalitos \\ 1500 Norte, CP 64460, Monterrey, N. L., México.
}

Received: May 22, 2020

doi:10.11114/ijsss.v8i4.4870
Accepted: June 15, $2020 \quad$ Available online: June 23, 2020

URL: https://doi.org/10.11114/ijsss.v8i4.4870

\begin{abstract}
Social Cognitive Theory explains how different personal, environmental and cognitive factors influence human behavior and it has been an important source of knowledge in the social and health sciences. It has been employed in research and practice in nursing, the science of caring. However, no critical analysis has been conducted to show the impact of Social Cognitive Theory in nursing. This article aims to conduct an analysis and evaluation of Social Cognitive Theory using the Fawcett and DeSanto-Madeya methodological framework and a systematic search of the literature. Social Cognitive Theory showed that even though is a non-disciplinary theory of health sciences, the clarity and simplicity of its content facilitates its use in understanding and addressing different phenomena of caring, the creation of middle-range theories and in professional education. The contribution of Social Cognitive Theory in nursing science has focused mainly on two aspects: firstly, on improving disciplinary knowledge with the practical context of health caring by understanding human behavior and its integration in interventions for the promotion, prevention and treatment of health, and secondly, on nursing professionals' education, highlighting the relevance of the interdisciplinary nature of knowledge.
\end{abstract}

Keywords: theory analysis, health care, social cognitive theory

\section{Introduction}

Social Cognitive Theory (SCT) is one of the social theories that integrate elements of psychology, sociology and political science. It was developed by Albert Bandura in 1977 to emphasize the role of observation and cognitive factors in learning and also to understand and predict behavior (Glanz, Rimer, \& Viswanath, 2015). The use of nursing theory in education, practice, and research provides a framework for understanding different phenomena of health care study, increases critical and creative thinking by assessing current knowledge, and probes unanswered questions that can generate new disciplinary knowledge for nursing (Lipscomb, 2017).

SCT has been used in different contexts, in clinical settings, health promotion, education, health policy initiatives and environmental education strategies (Glanz et al., 2015). In nursing, this theory has contributed to broadening the perspective on contextual and social factors in different health care settings. However, it has been questioned whether theories from other disciplines are adequate to guide the different phenomena of the nursing science. Therefore, it is necessary to know how the use of SCT has contributed to respond to the different areas of inquiry of the nursing discipline (Lipscomb, 2017). Within this context and the available scientific evidence, an analysis and evaluation of SCT was carried out using Fawcett and Desanto-Madeya (2013) approach. This approach consists of a methodological framework that includes two steps: Firstly, to analyze the origins of the theory and content and secondly, to evaluate the explanation of the origins, understanding of the content, logical consistency, theory generation, legitimacy; and contributions to the nursing discipline. This approach was used with the aim to increase the understanding and approximation of the use of SCT in nursing practice and research.

\section{Data Sources}

Three sources of information were considered, firstly, social foundations of thought and action, a social cognitive theory developed by Bandura in 1986. Secondly, health behavior and health education: theory, research, and practice by Glanz, Rimer and Viswanath (2008) and thirdly, complementary articles published by the author of the SCT. Additionally, a systematic review of literature. The search involved searching Cumulative Index to Nursing and Allied Health Literature (CINAHL) database to identify nursing articles available up to April 2020 that included SCT constructs. Thus, the keywords words used were nursing and social cognitive theory. 


\section{Analysis of the SCT}

\subsection{Origins}

Albert Bandura's first source of motivation was his academic formation that took place at a school with precarious resources and deficient teachers. Besides, he had to take charge of his own learning after a strike that took place in that school. Bandura described that learning process as "learning by oneself were the instruments of personal development, and not a theoretical abstraction. The lack of educational resources became an empowering factor that has helped me a lot, instead of becoming an insurmountable deficiency" (Bandura, 2006). In addition, Bandura mentions that he was influenced by behaviorists such as Watson and Thorndike and their work on learning by observation and its divergence and also by the work on social modeling proposed by Miller and Dollard on social learning and imitation with which he had discrepancies and that led Bandura to carry out research on the subject (Smith \& Hitt, 2005).

Bandura's theory began with a research process on the principles of learning within the human social context, from which his first formulation of the Theory of Social Learning emerged. Later, Bandura integrated elements of cognitive psychology that provided a greater scope in the understanding of human functioning from the perspective of the social origins of human thought and action (Glanz et al., 2008). According to Fawcett (2005), the vision of the world is formulated from the ontological and epistemic statements that reflect the nature of the human being and of knowledge itself, and are classified in three visions: reaction, reciprocal interaction and simultaneous action. In SCT, human functioning is explained as a reciprocal triad in which behavior, cognitive and personal factors operate as interactive determinants of each other. In accordance with the philosophical statements (Table 1), human functioning works as basic capabilities of human nature that reflect its vision of reciprocal interaction (Bandura, 1986).

Table 1. Philosophical statements of Social Cognitive Theory (Bandura, 1986)

\begin{tabular}{l} 
Symbolization capability \\
\hline The remarkable ability to use \\
symbols, which touch virtually \\
every aspect of people's lives \\
and provides them with a \\
powerful means of modifying \\
and adapting their environment.
\end{tabular}

Through symbols, people process and transit experiences within internal models that serve as guides for future actions.

Based on their knowledge and the power of symbolization, people can generate innovative courses of action.

\begin{tabular}{l} 
Vicarious capability \\
\hline The ability to learn by observation \\
allows people to acquire rules to \\
generate and regulate patterns of \\
behavior without having to gradually \\
formulate them by tedious trial and \\
error. \\
It is difficult to imagine a system of \\
social transmission in which the \\
language, lifestyles and institutional \\
practices of the culture are taught to \\
each new member only through the \\
selective reinforcement of fortuitous \\
behaviors, without the benefit of models \\
to exemplify these cultural patterns.
\end{tabular}

\begin{abstract}
Foresight capability
People do not simply react to their immediate environment; they are not directed by imprints from their past. Most of their behavior is purposeful and regulated by foresight.

Foresight is the product of reflective and generative thinking.

People anticipate the probable consequences of their prospective actions, they set goals for themselves and plan courses of action for known futures, whose established means are not only ineffective, but can also be harmful.

By representing predictable outcomes symbolically, people can turn future consequences into current motivators and regulators of predictable behavior.
\end{abstract}

\begin{tabular}{l} 
Self-regulatory capability \\
\hline People do not behave just to satisfy the preferences of \\
others. Much of their behavior is motivated and regulated \\
by standards and self-evaluation reactions to their own \\
actions.
\end{tabular}

Self-direction is exercised by influencing the external environment as well as incorporating Self-regulatory functions.

To be sure, self-regulatory functions are created from, and sometimes supported by, external influences.

self-reflective-capability
If there is one characteristic that is distinctively human, it is the
capacity for reflective self-awareness. This capacity allows people to
analyze their experiences and think about their own thought
processes.
People not only gain understanding through reflection, but they
also evaluate and alter their own thinking.
Among the types of thoughts that affect action, none is more
central or precautionary than people's judgments about their
abilities to deal effectively with different realities.
In self-appraisal efficacy, there are many sources of information that
must be processed and weighed through self-referential thinking.




\subsection{Approach}

In a social cognitive vision, people are not driven by internal forces or automatically configured and controlled by external stimuli, but by a reciprocal interaction. SCT recognizes that human behavior is the product of an interaction between personal, cognitive, behavioral and environmental factors. SCT gives special relevance to the potential abilities of people to alter or build environments that suit their individual and collective purposes. SCT has a unique approach to the social portion that recognizes the social origins of human thought and action (Bandura, 1986; Glanz et al., 2008).

According to Fawcett (2005), the categories of knowledge for nursing constitute an approach that makes it possible to understand people and different phenomena through different questions and bodies of knowledge. The SCT contains two categories namely, developmental and interactional. Bandura (1986) describes that most human behavior patterns are organized by individual experience and are preserved in neural codes, rather than being provided by congenital programming. This statement places SCT in the developmental category, which considers human beings with an inherent potential for change, generating coping responses to new situations, environmental factors, and internal stresses that sometimes peak and cause disruption that lead to further growth and development (Fawcett, 2005). According to Fawcett (2005), the interactional category explains how the perceptions of a human being about other people, the environment, situations and events, depends on the meaning assigned to the phenomenon and establishes. This category also has to do with the fact that human beings establish goals based on their perceptions of a given situation and social interaction with others. The latter is consistent with a view of interaction conceived as triadic reciprocal determinism, which refers to the mutual action between personal, environmental and behavioral factors and the effects produced by these (Bandura, 1986).

\subsection{Content}

A nursing theory is composed by concepts and propositions that are presented and classified according to the nursing philosophical metaparadigm which involves four main concepts: person, environment, health and nursing (Desanto-Madeya 2013). The analysis of the content implies finding the similarities between the four main concepts of the nursing metaparadigm with the concepts of SCT. Hence, the five categories of multidimensional concepts of the SCT namely, psychological determinants of behavior, environmental determinants of behavior, observational learning, self-regulation and moral detachment (Glanz et al., 2008) were considered for analysis. In order to describe the content of SCT, the definition of each nursing metaparadigm concept will be explained followed by the SCT concepts related to each of these nursing concepts.

As stated above, the first concept of the nursing metaparadigm refers to person. The person is understood as the human being, who is the focus of nursing caring (Fawcett \& Desanto-Madeya, 2013). In the SCT, the person is represented by the individual characteristics of a human being such as behavior, outcome expectations and self-regulation through non-relational propositions as shown in the definitions shown below.

Behavior: Is the product of an individual's learning history, current perceptions of the environment, and intellectual and physical abilities. Therefore, behavior can be changed through new learning experiences, guidance in adjusting perceptions and support for capacity development (Glanz et al., 2008, p. 176).

Outcome expectations: These are beliefs about the likelihood and value of consequences of behavioral choices (Glanz et al., 2008, p. 171). These include social, self-evaluation, self-efficacy and collective effectiveness outcome expectations, and their importance is established in relation to the health behaviors that an individual can assume.

Self-regulation: This refers to controlling oneself through self-control, goal setting, feedback, self-reward, self-instruction and enlisting social support (Glanz et al., 2008, p 171)

The second concept of the nursing metaparadigm, namely, environment refers to other human beings, physical environment and scenarios of delivery of nursing caring Fawcett and Desanto-Madeya (2013). In SCT environment is named environmental determinants of behavior and the main concept or this theory, that is, reciprocal determinism is described next as a relational proposition.

Reciprocal determinism: Environmental factors influence individuals and groups, but individuals and groups can also influence their environments and regulate their own behavior (Glanz et al., 2008, p 173).

The third concept of the nursing metaparadigm is health. It is described as the human life and death processes (Fawcett and Desanto-Madeya, 2013). The human life and death processes are not addressed in the SCT. Nevertheless, the SCT describes a non-relational proposition known as self-efficacy. Self-efficacy is an individual characteristic that affects life.

Self-efficacy: Consists of a person's beliefs about their ability to influence the quality of functioning and events that affect their lives (Glanz et al., 2008, p 172). It can be developed through four main forms: mastery of experience, social modelling, improvement of physical and emotional states, and verbal persuasion (Glanz et al., 2008, p.176).

The last concept of the metaparadigm is nursing. This refers to the actions carried out by the nursing professional on 
behalf of or in conjunction with the individual and the goals or results of the nursing actions (Fawcett and Desanto-Madeya, 2013). The SCT proposes concepts that suggest being theoretical sources for the provision of caring such as observational learning and facilitation. These two concepts are described below.

Observational learning: Learning to perform new behaviors by exposing them to interpersonal or media displays, particularly through peer-to-peer models (Glanz et al., 2008, p. 171).

Facilitation: This is the provision of new structures or resources that enable behaviors or make them easier to perform (Glanz et al., 2008, p.174).

\section{Evaluation of the SCT}

The evaluation is based on the analysis made and the systematic search for literature. The evaluation was done following these criteria: explanation of the origins of the model, comprehensiveness of the content, logical consistency, theory generation, legitimacy and contributions to the nursing discipline.

\subsection{Explanation of the Origins of the Model}

Bandura clearly expressed his motivations and he also stated the development he carried out to give more focus to his theory. This procedure resulted in an initial inductive focus that was a product of his life experience, in which he found essential elements related to learning and the ability for self-regulation. Therefore, through research, he developed his theory more in depth by incorporating the self-efficacy belief system (Bandura, 1986, 2006). By doing so, Bandura's theory showed a deductive development. Bandura's philosophical statements were based on the basic human capacities that are present and are inherent to human nature. These philosophical statements are also based on the capacity of human beings to carry out actions to maximize benefits and minimize costs (Glanz et al., 2008). There is an emphasis on the reciprocal interaction of personal, cognitive and environmental factors that model behavior.

\subsection{Comprehensiveness of Content}

The SCT displays a defined structure in the presentation of its concepts through a categorization that simplifies the analysis. As a non-disciplinary theory, it provides elements that facilitate the understanding of human behavior, as an inherent aspect of the interaction of the individual-nurse practitioner in the provision of caring.

SCT concepts are simple and clear. This fact makes it possible to equate them with the related concepts of the nursing metaparadigm. In this sense, person, the first concept of the nursing metaparadigm, is related to the concept of behavior, outcome expectations and self-regulation of the SCT. This, in turn, results in a definition of person as an individual that acts to maximize his or her benefits and achieves his or her self-control through different strategies. This concept of person that highlights self-control and agency coincides with the central purpose of nursing caring. The SCT describes the environment in terms of environmental factors and their influence on behavior, assigning these factors a central role to achieve a person's health behavior change. The concept of self-efficacy in the SCT becomes a key target in provision of caring.

Since SCT is non-disciplinary, it does not define nursing. However, if we take into account the metaparadigmatic definition in Fawcett's and Desanto-Madeya (2013) approach, according to which nursing is considered as the actions carried out by the nursing professional, SCT provides elements that can contribute to the design or adaptation of caring interventions that allow the achievement of goals in a practical nursing situation. Likewise, different elements derived from the category of concepts of observational learning can be used in the implementation of the nursing training programs and the facilitation approach, These concepts can serve as a tool for the development of new competencies in students, taking into account that "by observing others, one creates rules of behavior, and on future occasions, this codified information serves as a guide for action" (Bandura, 1986).

\subsection{Logical Consistency}

SCT is logically consistent. It reflects the vision of reciprocal interaction throughout the description of its philosophical statements. It contemplates behavior modeling as part of the relationship between the environment and the individual that fosters the development of individual's abilities and personal and cognitive factors such as plasticity, self-reflection and self-regulation. About this, Bandura (1986) mentioned that "behavior, personal and cognitive factors and environmental influences, all operate interactively as determinants of each other".

In accordance with the world view, SCT reflects the knowledge categories of development and interaction. These categories can be exemplified through the statements about plasticity which "is intrinsic to human nature and that depends on neurophysiological mechanisms that have been involved over time and which provide the capability to develop some characteristics that are distinctively human... behavior has some organized patterns innately present at birth; other patterns appear after a period of maturation" (Bandura, 1986). 


\subsection{Theory Generation}

It refers to the possibility that the most concrete concepts and propositions are deduced from the model. Resnick formulated the Middle Range Theory of Self-Efficacy, based on one of the core concepts of SCT, and stated that in order to determine self-efficacy, the individual must have the possibility of self-evaluation or the ability to compare himself with some type of evaluative criteria to judge his performance capacity and define self-efficacy expectations. This theory has been widely used in health promotion (Smith \& Liehr, 2018).

According to Alligood (2014), SCT was one of the theoretical sources of Nola J. Pender's Health Promotion Model, a middle range theory that defined self-efficacy as one of its central constructs. Pender analyzed this construct in her research program to understand how self-efficacy affected adolescent girls' effort and affective responses to the challenge of physical activity and defined "perceived self-efficacy as the judgment of one's ability to organize and execute health-promoting behavior". This concept was included within the following theoretical statements: (a) perceived competence or self-efficacy in executing a given behavior increases the probability of commitment to action and actual performance of the behavior; (b) greater perceived self-efficacy results in fewer perceived barriers to a specific health behavior; and (c) positive affection for a behavior results in greater perceived self-efficacy, which, in turn, may result in an increase of positive affection.

\subsection{Legitimacy}

This refers to the results of the use of the model in the different nursing areas and the soundness of the model's content. At this point, the literature search carried out in CINAHL was considered as a support to the evaluation of the use of the theory in terms of its usefulness, congruence and social significance. According to Glanz et al. (2008), the SCT provides a comprehensive and well-supported conceptual framework for understanding the factors that influence human behavior and learning processes. SCT offers information on a wide range of health-related issues that have facilitated the design of interventions to respond to health problems.

SCT provides concepts that facilitate a comprehensive approach that includes the family and an understanding of the different personal, cognitive and environmental factors that could influence health behavior change. According to Mareno (2010), nursing interventions can be used to increase the opportunity for personal mastery experiences (active achievement), include family or support systems as models in the process of behavior change (vicarious experience), use professional communication skills to help patients and families identify facilitators for change (verbal persuasion), and provide nursing caring that helps alleviate anxiety (physiological feedback).

Different uses of the SCT have been documented in nursing research (Table 2). In the area of patient education, by evaluating the effectiveness of the delivery of the intervention by the nurse, measuring its impact on the target population or on the change in nurse's habits. Also, SCT has been applied in the understanding and analysis of situations related to home care and to identify factors that affect the delivery of the service, or, to understand the basis of the effectiveness of the interventions executed by nurses in the caring of the patient at home.

Table 2. Published studies for nursing research and practice guided by the SCT

\begin{tabular}{|c|c|c|c|c|c|}
\hline Nursing care phenomenon & Area & Employed concepts & Use of the theory* & Population & Citation \\
\hline Cessation of tobacco use & Patient education & Self-efficacy & Applied & Nurses & $\begin{array}{c}\text { Preechawong, } \\
\text { Vathesathogkit y } \\
\text { Suwanratsamee } \\
(2011)\end{array}$ \\
\hline Stroke & Patient education & Self-efficacy & Applied & Nurses & $\begin{array}{l}\text { Mayer, Andrusyszyn, } \\
\text { y Iwasiw (2005) }\end{array}$ \\
\hline Stroke & Patient education & Self-efficacy & Applied & Adults & Ireland et al. (2010) \\
\hline Cardiorespiratory arrest & $\begin{array}{c}\text { Cardiorespiratory } \\
\text { nursing }\end{array}$ & $\begin{array}{l}\text { Outcome } \\
\text { expectations, } \\
\text { Self-efficacy }\end{array}$ & Applied & Nurses & $\begin{array}{c}\text { Dougherty, } \\
\text { Johnson-Crowley, } \\
\text { Lewis y Thompson } \\
(2001)\end{array}$ \\
\hline Pregnancy & $\begin{array}{l}\text { Community } \\
\text { nursing }\end{array}$ & Self-efficacy & Applied & $\begin{array}{l}\text { Pregnant } \\
\text { women }\end{array}$ & $\begin{array}{l}\text { Holland, Yinglin, } \\
\text { Kitzman, Dozier y } \\
\text { Olds (2014) }\end{array}$ \\
\hline Dementia & Geriatric nursing & Self-efficacy & Testing & Older adults & $\begin{array}{l}\text { López, y Guarino, } \\
\text { (2013) }\end{array}$ \\
\hline Prevention of hip fracture & Geriatric nursing & $\begin{array}{l}\text { Environmental } \\
\text { factors of behavior }\end{array}$ & Applied & Older adults & $\begin{array}{c}\text { Nahm, Resnick, } \\
\text { DeGrezia y } \\
\text { Brotemarkle (2009) }\end{array}$ \\
\hline Depression and anxiety & $\begin{array}{c}\text { Maternal-perinatal } \\
\text { nursing }\end{array}$ & Self-efficacy & Applied & $\begin{array}{c}\text { Pregnant } \\
\text { women }\end{array}$ & Baek, y Park (2013) \\
\hline
\end{tabular}




\begin{tabular}{|c|c|c|c|c|c|}
\hline Nursing care phenomenon & Area & Employed concepts & Use of the theory* & Population & Citation \\
\hline Patient safety & $\begin{array}{c}\text { Medical-surgical } \\
\text { nursing }\end{array}$ & Self-efficacy & Applied & Nurses & Raica (2009) \\
\hline Hemodialysis & $\begin{array}{c}\text { Nephrology } \\
\text { nursing }\end{array}$ & Self-efficacy & Applied & Nurses & $\begin{array}{l}\text { Ludlow, Gaudine y } \\
\text { Jacobs (2007) }\end{array}$ \\
\hline Prostate cancer & Oncology nursing & Self-efficacy & Applied & Nurses & $\begin{array}{l}\text { Maliski, Clerkin y } \\
\text { Litwin (2004) }\end{array}$ \\
\hline $\begin{array}{l}\text { Advanced } \\
\text { practice }\end{array}$ & Pediatric nursing & Self-efficacy & Building & NA & Manila (2014) \\
\hline Pain management & Pediatric nursing & Self-efficacy & Applied & $\begin{array}{l}\text { Pediatric } \\
\text { nurses }\end{array}$ & $\begin{array}{c}\text { Stanley y Pollard } \\
\text { (2013) }\end{array}$ \\
\hline Asthma & Pediatric nursing & Self-efficacy & Applied & Nurses & $\begin{array}{l}\text { O'Laughlen, Hollen } \\
\text { y Ting (2009) }\end{array}$ \\
\hline Type II diabetes & Patient education & Self-efficacy & Testing & $\begin{array}{l}\text { People with } \\
\text { Type II DM }\end{array}$ & Jiang et al. (2019) \\
\hline Changes in dietary habits & Patient education & Self-efficacy & Informed & Nurses & $\begin{array}{l}\text { Jackson, D'Avolio, y } \\
\text { Gropper (2019) }\end{array}$ \\
\hline $\begin{array}{l}\text { Self-care behaviors in } \\
\text { heart failure }\end{array}$ & Patient education & Self-efficacy & Building & NA & $\begin{array}{c}\text { Herber, Kastaun, } \\
\text { Wilm, y Barroso } \\
(2019)\end{array}$ \\
\hline
\end{tabular}

* The classification was made according to the categorization by Painter, Borba, Hynes, Mays, \& Glanz, 2008

Table 3 shows the impact of SCT on nursing education. It has been used in the design of interventions on clinical simulation, development of practical skills, computer-mediated learning strategies and in nursing procedures. These nursing education practices aim at achieving a greater approximation of the students between the simulated scenarios and the real world, so as to influence better performance in the context of nursing practice. Other reported uses in education were the combination of the SCT with the theory of cross-cultural caring, to understand the phenomenon of adaptation to the change experienced by nursing students towards practice, and the design of interventions to favor the process of change of nurses with international training.

Table 3. Published studies on nursing education guided by the SCT

\begin{tabular}{|c|c|c|c|c|}
\hline Education in nursing & Employed concepts & $\begin{array}{l}\text { Use of the } \\
\text { theory* }\end{array}$ & Population & Citation \\
\hline Information literacy & Self-efficacy & Applied & Nurses & $\begin{array}{l}\text { Robertson y Felicilda-Reynaldo } \\
\text { (2015) }\end{array}$ \\
\hline $\begin{array}{l}\text { Computer mediated } \\
\text { learning }\end{array}$ & Self-efficacy & Applied & Nursing students & $\begin{array}{c}\text { Babenko-Mould, Andrusyszyn y } \\
\text { Goldenberg (2004) }\end{array}$ \\
\hline Cultural competence & Self-efficacy & Informed & Nursing students & Long $(2016)$ \\
\hline Cultural competence & Self-efficacy & Applied & Nursing students & Liu, Mao y Barnes-Willis (2008) \\
\hline Learning strategies & Self-regulation & Applied & Nursing students & Mullen (2007) \\
\hline Clinical skills & Self-efficacy & Applied & Nursing students & $\begin{array}{c}\text { Piscotty, Grobbel y Huey-Ming } \\
\text { (2011); Laschinger, McWilliam y } \\
\text { Weston (1999); Pollard, Kuiper y } \\
\text { Meredith (2010) }\end{array}$ \\
\hline Clinical skills & Self-efficacy & Testing & Nursing students & $\begin{array}{c}\text { Oetker-Black, Kreye, Underwood, } \\
\text { Price y DeMetro (2014) }\end{array}$ \\
\hline Clinical practice & Self-efficacy & Applied & Nurses & Koch, et al. (2011) \\
\hline Nursing procedures & $\begin{array}{l}\text { Vicarious experiences, } \\
\text { self-efficacy }\end{array}$ & Applied & Nursing students & Liu, Mao y Barnes-Willis (2008) \\
\hline Clinical simulation & $\begin{array}{l}\text { Environmental, } \\
\text { cognitive and } \\
\text { behavioral factors }\end{array}$ & Applied & Nursing students & $\begin{array}{l}\text { Burke y Mancuso (2012); Owen y } \\
\text { Ward-Smith (2014) }\end{array}$ \\
\hline Clinical instruction & Observational learning & Informed & Nursing students & $\begin{array}{c}\text { Gordon, Carmany, Baker y Goliat } \\
(2018)\end{array}$ \\
\hline Virtual teaching & Self-efficacy & Applied & Nursing students & Cadet $(2018)$ \\
\hline
\end{tabular}

In terms of social congruence, SCT brings a broader view to the nursing discipline of the phenomenon of caring, allowing an understanding of all those factors that can interfere with the provision of caring or education, as well as the interaction between these that can lead to or limit a change the individual's health behavior. Whitehead (2001) states that the power of social cognitive theories resides in their ability to highlight an individual's reasons for considering and possibly adopting 
any health-related behavioral change. SCT has also been used in education to design strategies that facilitate the transfer of knowledge from nursing professionals to the context of practice. Social significance was not assessed, as SCT is not a disciplinary theory of nursing and does not correspond to the definition of the value that the nursing model brings to the health conditions of individuals.

\subsection{Contributions to the Nursing Discipline}

The use of non-disciplinary theories contributes to the identification of multiple aspects that determine the health-disease process and that are necessary to provide comprehensive caring in nursing (Medeiros et al, 2016). Among these aspects is behavior and its determinants that make up the central construct of SCT, especially the mostly used concept in nursing research, namely, self-efficacy. The concept of self-efficacy expands the body of nursing knowledge in the approach to caring as it integrates elements for the understanding of health behaviors, the focus of interventions and a greater extension of nursing practice towards interdisciplinary scenarios that can contribute to the construction of new horizons for nursing in health promotion and caring of the person in the community.

The use of SCT can generate a theoretical base to bridge the gap between disciplinary knowledge and practice through the construction of strategies that maximize human potential, generation of greater appropriation of this knowledge, and optimization of the experience in practice scenarios for health professional trainees and in the processes of adaptation to different situations of nursing domain.

\section{Conclusion}

SCT is a sound theory of psychology that has shown clarity and consistency between concepts and propositions. In consequence, its application in nursing research has permitted the generation of middle range theories, concept derivation and understanding of health phenomena that have contributed to building the body of knowledge in nursing. SCT has also guided the development of caring interventions for health promotion, disease prevention and treatment, as well as, understanding and analysis of different clinical and home caring contexts in nursing practice. In Education, SCT has provided a theoretical baseline in the design of teaching/learning strategies for nursing professional trainees. In conclusion, SCT provides a theoretical framework to understand different health phenomena in research, to design interventions in practice and to carry out innovations in teaching process in nursing education.

\section{Limitations of the Study}

There are two aspects of limitations regarding the analysis and evaluation of SCT in this article. First, the systematic review of literature was done resorting to the Cumulative Index to Nursing and Allied Health Literature (CINAHL) database, which could have reduced the scope of the analysis and evaluation of SCT and therefore, its extensive use to other areas of nursing. Second, the articles taken from the database were written in English. Further studies can include a broader systematic review of literature.

\section{Acknowledgements}

The authors acknowledge the funding received from the National Council for Science and Technology (CONACyT, grant 626549), the Center for Research and Development in Health Sciences provision of the required resources and the Sub-Directorate for Graduate and Research of the Faculty of Nursing of the Autonomous University of Nuevo León for their advice in the development of this article. Authors express their gratitude to Julia Posada for her proofreading of this document.

The authors declare that there is no conflict of interest.

\section{References}

Alligood, M. R. (2014). Nursing Theorists and Their Work (8th ed.). St. Louis, Missouri: Elsevier Mosby.

Babenko-Mould, Y., Andrusyszyn, M. A., \& Goldenberg, D. (2004). Effects of computer-based clinical conferencing on nursing students' self-efficacy. The Journal of Nursing Education, 43(4), 149-155. https://doi.org/10.3928/01484834-20040401-08

Baek, E. S., \& Park, H. J. (2013). Effects of a case management program on self-efficacy, depression and anxiety in pregnant women with gestational diabetes mellitus. Korean Journal of Women Health Nursing, 19(2), 88-98. https://doi.org/10.4069/kjwhn.2013.19.2.88

Bandura, A. (1986). Social foundations of thought and action: a social cognitive theory. Englewood Cliffs, N.J: Prentice-Hall.

Bandura, A. (2006). A history of psychology in autoebiography. Washington, D.C., US: American Psychological Association.

Burke, H., \& Mancuso, L. (2012). Social Cognitive Theory, metacognition, and simulation learning in nursing 
education. Journal of Nursing Education, 51(10), 543-548. https://doi.org/10.3928/01484834-20120820-02

Cadet, M. J. (2018). Self-Perception of readiness to learn and Self-Efficacy among nursing students in an online baccalaureate program. Journal of Informatics Nursing, 3(2), 23-27.

Dougherty, C. M., Johnson-Crowley, N. R., Lewis, F. M., \& Thompson, E. A. (2001). Theoretical development of nursing interventions for sudden cardiac arrest survivors using social cognitive theory. ANS. Advances in Nursing Science, 24(1), 78-86. https://doi.org/10.1097/00012272-200109000-00009

Fawcett, J. (2005). Contemporary nursing knowledge: analysis and evaluation of nursing models (2nd ed.). Philadelphia, PA: F.A. Davis Company.

Fawcett, J., \& Desanto-Madeya, S. (2013). Contemporary nursing knowledge. Analysis and evaluation of nursing models and theories (3rd ed.). Philadelphia, PA: F.A. Davis Company.

Ford-Gilboe, M., Laschinger, H. S., Laforet-Fliesser, Y., Ward-Griffin, C., \& Foran, S. (1997). The effect of a clinical practicum on undergraduate nursing students' self-efficacy for community-based family nursing practice. The Journal of Nursing education, 36(5), 212-219.

Glanz, K., Rimer, B. K., \& Viswanath, K. (2008). Health behaviour and health education: theory, research, and practice (4th ed.). San Francisco, CA: Jossey-Bass.

Glanz, K., Rimer, B. K., \& Viswanath, K. (2015). Health behavior: theory, research, and practice (5th ed.). San Francisco, CA: Jossey-Bass.

Gordon, K. A., Carmany, K. E., Baker, J. R., \& Goliat, L. M. (2018). Innovative teaching for undergraduate nursing students through mastery modeling. Nursing Education Perspectives, 39(3), 184-186. https://doi.org/10.1097/01.NEP.0000000000000234

Herber, O. R., Kastaun, S., Wilm, S., \& Barroso, J. (2019). From qualitative meta-summary to qualitative meta-synthesis: Introducing a new situation-specific theory of barriers and facilitators for self-care in patients with heart failure. Qualitative health research, 29(1), 96-106. https://doi.org/10.1177/1049732318800290

Holland, M. L., Xia, Y., Kitzman, H. J., Dozier, A. M., \& Olds, D. L. (2014). Patterns of visit attendance in the nurse-family partnership program. American Journal of Public Health, 104(10), e58-e65. https://doi.org/10.2105/AJPH.2014.302115

Ireland, S., MacKenzie, M., Gould, L., Dassinger, D., Koper, A., \& LeBlanc, K. (2010). Nurse case management to improve risk reduction outcomes in a stroke prevention clinic. Canadian Journal of Neuroscience Nursing, 32(4), 7-13.

Jackson, K., D'Avolio, D., \& Gropper, S. (2019). Choosing coaching frameworks for promoting diet modifications. British Journal of Nursing, 28(22), 1456-1460. https://doi.org/10.12968/bjon.2019.28.22.1456

Jiang, X., Jiang, H., Li, M., Lu, Y., Liu, K., \& Sun, X. (2019). The mediating role of self-efficacy in shaping selfmanagement behaviors among adults with type 2 Diabetes. Worldviews on evidence-based nursing, 16(2), 151-160. https://doi.org/10.1111/wvn.12354

Koch, J., Salamonson, Y., Du, H. Y., Andrew, S., Frost, S. A., Dunncliff, K., \& Davidson, P. M. (2011). Value of web-based learning activities for nursing students who speak english as a second language. Journal of Nursing Education, 50(7), 373-380. https://doi.org/10.3928/01484834-20110331-02

Laschinger, H., McWilliam, C., \& Weston, W. (1999). The effects of family nursing and family medicine clinical rotations on nursing and medical students' self-efficacy for health promotion counseling. Journal of Nursing Education, 38(8), 347-356.

Lipscomb, M. (2017). Social theory and nursing. New York, NY: Routledge. https://doi.org/10.4324/9781315644066

Liu, L., Mao, C., \& Barnes-Willis, L. (2008). Cultural self-efficacy of graduating baccalaureate nursing students in a state funded university in the Silicon Valley. Journal of Cultural Diversity, 15(3), 100-107.

Long, T. (2016). Influence of international service learning on nursing students' self efficacy towards cultural competence. Journal of Cultural Diversity, 23(1), 28-33.

Lopez, R. P., \& Guarino, A. J. (2013). Psychometric evaluation of the surrogate decision-making self-efficacy scale. Research in Gerontological Nursing, 6(1), 71-76. https://doi.org/10.3928/19404921-20121203-02

Ludlow, V., Gaudine, A., \& Jacobs, M. (2007). The design of a hemodialysis nursing orientation program. CANNT Journal, 17(2), 44-47. 
Maliski, S., Clerkin, B., \& Litwin, M. (2004). Describing a nurse case manager intervention to empower low-income men with prostate cancer. Oncology Nursing Forum, 31(1), 57-64. https://doi.org/10.1188/04.ONF.57-64

Manila, V. M. (2014). Parental efficacy in nursing practice: a concept analysis and derivation. International Journal for Human Caring, 18(4), 7-13. https://doi.org/10.20467/1091-5710-18.4.7

Mareno, N. (2010). Concepts and Theories to the Care of Vulnerable Populations. In Caring for the vulnerable perspectives in Nursing Theory, Practice, and Research (3rd ed). Burlington, MA: Jones \& Bartlett Learning.

Mayer, C., Andrusyszyn, M. A., \& Iwasiw, C. (2005). Codman award Paper: self-efficacy of staff nurses for health promotion counselling of patients at risk for stroke. Axone (Dartmouth, N.S.), 26(4), 14-21.

Medeiros, L. P. De, Dantas, M., Melo, M., Enders, B. C., Silva, S., Xavier, D. M., ... Costa, F. (2016). Utilized Theories by Nursing in the Care of People with an Ostomy: Integrative Review. Open Journal of Nursing, 6(August), 600-609. https://doi.org/http://dx.doi.org/10.4236/ojn.2016.68064

Mullen P. A. (2007). Use of self-regulating learning strategies by students in the second and third trimesters of an accelerated second-degree baccalaureate nursing program. The Journal of Nursing Education, 46(9), 406-412. https://doi.org/10.3928/01484834-20070901-05

Nahm, E. S., Resnick, B., DeGrezia, M., \& Brotemarkle, R. (2009). Use of discussion boards in a theory-based health web site for older adults. Nursing Research, 58(6), 419-426.

https://doi.org/10.1097/NNR.0b013e3181bee6c4

Oetker-Black, S. L., Kreye, J., Underwood, S., Price, A., \& DeMetro, N. (2014). Psychometric evaluation of the Clinical Skills Self-Efficacy Scale. Nursing education perspectives, 35(4), 253-256. https://doi.org/10.5480/11-739.1

O'Laughlen, M., Hollen, P., \& Ting, S. (2009). An intervention to change clinician behavior: conceptual framework for the multicolored simplified asthma guideline reminder (MSAGR). Journal of the American Academy of Nurse Practitioners, 21(8), 417-422. https://doi.org/10.1111/j.1745-7599.2009.00429.x

Owen, A. M., \& Ward-Smith, P. (2014). Collaborative learning in nursing simulation: near-peer teaching using standardized patients. Journal of Nursing Education, 53(3), 170-173.

https://doi.org/10.3928/01484834-20140219-04

Painter, J. E., Borba, C. P. C., Hynes, M., Mays, D., \& Glanz, K. (2008). The use of theory in health behavior research from 2000 to 2005: a systematic review. Annals of Behavioral Medicine, 35(3), 358-362. https://doi.org/10.1007/s12160-008-9042-y

Piscotty, R., Grobbel, C., \& Tzeng, H. M. (2011). Integrating quality and safety competencies into undergraduate nursing using student-designed simulation. The Journal of Nursing Education, 50(8), 429-436. https://doi.org/10.3928/01484834-20110429-04

Pollard, D. L., Kuiper, R., \& Meredith, C. M. (2010). Camp BONES: a partnership initiative to engage underrepresented adolescents in a career in nursing at the baccalaureate level. The Journal of nursing education, 49(2), 108-115. https://doi.org/10.3928/01484834-20091118-03

Preechawong, S., Vathesathogkit, K., \& Suwanratsamee, S. (2011). Effects of tobacco cessation counseling training on thai professional nurses' self-efficacy and cessation counseling practices. Pacific Rim International Journal of Nursing Research, 15(1), 3-12.

Raica D. A. (2009). Effect of action-oriented communication training on nurses' communication self-efficacy. Medsurg Nursing: Official Journal of the Academy of Medical-Surgical Nurses, 18(6), 343-360.

Robertson, D. S., \& Felicilda-Reynaldo, R. F. (2015). Evaluation of graduate nursing students' information literacy self-efficacy and applied skills. The Journal of Nursing Education, 54(3 Suppl), S26-S30.

https://doi.org/10.3928/01484834-20150218-03

Smith, K. G., \& Hitt, M. A. (2005). Great minds in management: The Process of Theory Development. New York, NY: Oxford University Press.

Smith, M. J., \& Liehr P. R. (2018). Middle Range Theory for Nursing (4th ed.). New York, NY: Springer Publishing Company. https://doi.org/10.1891/9780826159922

Stanley, M., \& Pollard, D. (2013). Relationship between knowledge, attitudes, and self-efficacy of nurses in the management of pediatric pain. Pediatric Nursing, 39(4), 165-171.

Whitehead, D. (2001). A social cognitive model for health education/health promotion practice. Journal of Advanced 
Nursing, 36(3), 417-425. https://doi.org/10.1046/j.1365-2648.2001.01973.x

\section{Copyrights}

Copyright for this article is retained by the author(s), with first publication rights granted to the journal.

This is an open-access article distributed under the terms and conditions of the Creative Commons Attribution license which permits unrestricted use, distribution, and reproduction in any medium, provided the original work is properly cited. 